\title{
Is Erythropoietin Combining with Therapeutic Hypothermia an Efficient and Safe Therapy in Neonatal Hypoxic Ischemic Encephalopathy: A Prospective and Randomized Clinical Trial
}

\section{Liang-yan Zou}

Children's Hospital of Fudan University https://orcid.org/0000-0003-4986-3168

Bing-xue Huang

Children's Hospital of Fudan University

Peng Zhang

Children's Hospital of Fudan University

\section{Guo-qiang Cheng}

Children's Hospital of Fudan University

Chun-mei Lu

Children's Hospital of Fudan University

Jin-qiao Sun

Children's Hospital of Fudan University

Wen-hao Zhou

Children's Hospital of Fudan University

Lai-shuan Wang ( $\square$ laishuanwang@fudan.edu.cn )

Research article

Keywords: neonate, hypoxic ischemic encephalopathy, biomarker, brain image, neurodevelopmental outcome

Posted Date: May 13th, 2020

DOI: https://doi.org/10.21203/rs.3.rs-26962/v1

License: (c) (i) This work is licensed under a Creative Commons Attribution 4.0 International License. Read Full License 


\section{Abstract}

\section{Background}

To evaluate the efficacy and safety of erythropoietin (Epo) combined with therapeutic hypothermia (TH) in neonatal hypoxic-ischemic encephalopathy (HIE).

\section{Methods}

A total of 78 term infants with HIE were assigned randomly to receive Epo $(n=40)$ or placebo $(n=38)$. All infants received $\mathrm{TH}$. Blood samples before $\mathrm{TH}$, after $\mathrm{TH}$ and after Epo/placebo were collected for measuring TH associated adverse events, Epo associated factors and potential neural biomarkers. Basal ganglia/ watershed (BG/W) scoring system was used to assess brain injury in MRI. Neurodevelopmental evaluations were performed at 18 months by using BayleyScales of Infant Development II (Bayley II).

Results

Epo-treated group tend to have lower serum creatine kinase (CK) concentration (114 vs 202, $\mathrm{P}=.04$ ) and higher serum $\mathrm{K}^{+}, \mathrm{Mg}^{2+}$ concentration ( 5.0 vs $4.5, \mathrm{P}=.03 ; 1.0$ vs $0.9, \mathrm{P}=.02$ ) than control group after intervention. Brain MRI was performed in $65(83 \%)$ neonatal. Totally brain injury score was in even distribution between two groups (median, 0 vs $0, P=.61$ ), but injury region in cortex plus basal nuclei comparing with in basal nuclei solely was less common in the Epo than in the control group $(21 \%$ vs $31 \%$, $\mathrm{P}=.046)$. Only forty patients $(40 / 78,51 \%)$ succeeded in achieving 18 -month follow up data. The totally adverse outcomes were trend to decline in the Epo group ( $35 \%$ vs $60 \%, P=.21)$. No adverse events were ascribed to Epo treatment.

\section{Conclusions}

The combination of Epo and TH is proved to be feasible, safe and potential effective.

Trial registration: ChiCTR-TRC-14004532, date of registration: April 18th, 2014.

\section{Background}

Hypoxic-ischemic $(\mathrm{HI})$ induced brain injury at newborn remains a concernful problem, affecting 26 per 1,000 live births in developing countries, and contributing to an estimated $22 \%$ of deaths in neonatal period.(1) In the vast territory of China, there are different level of hygiene between urban and rural areas, caused hypoxic-ischemic encephalopathy (HIE) is still a main cause of neonatal death. The traditional treatment for HIE is limited to supportive methods, to maintain physiologic signs, which played restricted role in decreasing mortality and improving neurodevelopmental prognosis. Multicenter clinical trials assessing the efficacy of therapeutic hypothermia $(\mathrm{TH})$ demonstrated improved outcomes for term neonates with moderate HIE, and now TH is the standard of care in many countries. $(1,2)$ Although TH is clearly beneficial in reducing the risk of death or major neurodevelopmental disability from $60 \sim 65-50 \%$, 
$(2,3)$ over $40 \%$ infants with moderate/ severe HIE received this therapy still experienced disabilities, including cerebral palsy, cognitive impairment and epilepsy. $(2,4)$ Adjuvant therapies to further inspiring outcomes of HIE are imperatively needed.

Epo, a glycoprotein used widely in treating anemia, is affirmed to be neuroprotective medicine for HIE. As Epo binds to receptor, activation of intracellular signaling pathways may trigger a function in preventing apoptosis of cell.(5) Other short-term neuroprotective mechanisms contained neurotrophic, anti-oxidant and anti-inflammatory. Epo also may be responsible for brain repair through erythropoiesis, angiogenesis, oligodendrogenesis and neurogenesis. $(6,7)$ A phase $\triangle$ trail demonstrated Epo at $1000 \mathrm{U} / \mathrm{kg}$ per dose given intravenously in conjunction with $\mathrm{TH}$ is safe and produces plasma concentrations that are similar neuroprotective in animals.(8) Continuously phase $₫$ trail concluded that Epo combing TH for HIE infant may result in less MRI brain injury and improved motor function at 12-month, but when the researchers removed two patients who had been met with excluded criterias, the improvement in motor function attributed by Epo were not statistically significant.(9)

Thus, the long-term function of Epo is still need further study. Rarely study mentioned the change level of potential neurological prognosis associated serum biochemical markers. Based on our previcous Chinacooling RCT study(10), we had gone further to conduct a prospective, double-blinded, placebo-controlled, phase $\otimes$ trial, exploring easy-measuring potential neurological prognosis associated biomarkers and using a new kind of MRI scoring system, to determine whether Epo as an adjuvant therapy to $\mathrm{TH}$ is effective and safe.

\section{Methods}

In this prospective, randomized, double-blinded, placebo-controlled trial, we enrolled 78 newborns at $>36$ weeks gestational age diagnosed HIE according to standard from pediatrics section of the Chinese Medical Association, which was similar to our previous RCT study protocol. The randomization codes were generated by computer and supplied in numbered, sealed envelopes. Participants were from hospitalized during May 1, 2014 to May 1, 2018 on Department of Neonatology, Children's Hospital of Fudan University. This study was approved by the Ethics Committee. Written informed consent was obtained from the parents.

\section{Hypothesis}

We hypothesized that high doses of Epo (1000 U/kg per dose) given combined with TH will release the level of biomarkers associated with poor prognosis, decrease the brain injury in MRI, improve the longterm neurological outcome and be safe.

\section{Population}


All participants met four inclusion criteria: (1) $\geq 36$ weeks gestational age, $\geq 2500 \mathrm{~g}$ birth weight, within 6 hours of age; (2) $\mathrm{pH}<7.00$ or base deficit $\geq 15 \mathrm{mmol} / \mathrm{L}$ in cord or arterial blood within 60 minutes of birth; (3) perinatal emergency events (i.e. severe late fetal / abnormal deceleration, umbilical cord prolapse, rupture of the umbilical cord, rupture of the uterus) with 5 minute Apgar score $<5$ or need for resuscitation (including endotracheal or mask ventilation) at 10 minutes after birth; (4) evidence of encephalopathy, such as seizures, disturbance of consciousness

(lethargy, stupor, or coma), abnormal reflexes.(11-13)

Additional exclusion criteria including: congenital metabolic disorder or anomaly; severe perinatal infectious; head trauma or skull fracture causing intracranial hemorrhage.

Withdrawal standards: (1) intractable pulmonary hypertension; (2) hypotension (MAP $\leq 30 \mathrm{mmHg}$ ) insensitive to treat; (3) severe arrhythmia; (4) platelet count < $50 \times 10^{9 / L}$; (5) oliguria (urine volume < $0.5 \mathrm{~mL} / \mathrm{kg} / \mathrm{h}$ continuous for 24 hours and progressive aggravated azotemia); (6) severe infections with clinical and laboratory evidence; (7) scleroderma; (8) parents/legal guardians refuse to continue.

\section{Intervention}

Within 6 hours after birth, participants began TH continuously for 72 hours. Epo group were given $1000 \mathrm{U} / \mathrm{kg}$ per dose human recombinant erythropoietin ( $\mathrm{r}-\mathrm{Hu}-\mathrm{Epo}$ ) intravenously every other day for two weeks and the placebo group given an equal volume of physiological saline. The basal treatment and supportive care were identical between two groups: intravenous nutrition to meet the energy requirement; when seizures occurred, phenobarbital was used first at $20 \mathrm{mg} / \mathrm{kg}$, with maintenance dose of $5 \mathrm{mg} / \mathrm{kg} . \mathrm{d}$; dopamine, fentanyl or antibiotics were utilized when necessary.

\section{Outcome Measurements}

\section{Potential neurological biomarkers}

Participants will have at least two blood samples (before TH and after TH) for potential neurological biomarkers serum level detecting. Reviewed previous study, we picked up several potential biomarkers which were common detected in clinical uses including: creatine kinase (CK), lactate dehydrogenase $(\mathrm{LDH}), \mathrm{Na}^{+}, \mathrm{K}^{+}, \mathrm{Mg}^{2+}$ and $\mathrm{Ca}^{2+}$. $\mathrm{CK}$, usually used in judging myocardial ischemic injury, have also been found that high level was associated with serious brain damage.(14) LDH, one of the important enzyme participating in anaerobic glycolysis and gluconeogenesis, have been demonstrated the level was significantly higher in the HIE group.(15) Besides, HI triggers the disruption of ionic homeostasis, characterizing by enhanced $\mathrm{K}^{+}$efflux and $\mathrm{Na}^{+}, \mathrm{Ca}^{2+}$ influx, which has been considered as the most important alteration which eventually leads to cell death or injury. $(16,17)$ Evidences showed $\mathrm{Mg}^{2+}$ may 
keep cell membrane stabilization, inhibits free radical production and decreases secondary inflammation. $(18,19)$ The laboratory technician was blinded to the group distribution.

\section{Neuroimaging}

Neonatal brain MRI was performed within 14 days of age. The BG/W score system, obtained basing on combining damage region, with the first-echo T2-weighted sequence, was the useful score for predicting motor outcome at 3 and 12 months and cognitive outcome at 12 months. The score ranged from 0 to 4 , and higher scores were given for more extensive damage. Detailed scoring criteria as below: $0=$ normal; 1 $=$ abnormal signal in basal nuclei (BG or thalamus); $2=$ abnormal signal in cortex; $3=$ abnormal signal in cortex and basal nuclei (BG or thalamus); $4=$ abnormal signal in entire cortex and basal nuclei.(20) Two central reviewers after training were blinded to treatment allocation, independently scored brain MRI outcome.

\section{Neurodevelopmental Outcomes}

Forty patients $(40 / 78,51 \%)$ succeeded in achieving 18-month follow up data. In the Epo group, three infants died after discharged from hospital at the age around three days to one month. In the placebo group, three patients died during their hospitalization (two of persistent pulmonary hypertension, one of multiple organ failure) and one died after left hospital for one week. The Bayley II developmental scale results showed that the Epo group were likely to perform better in MDI score (mean, 88 vs $81, P=.23$ ) and PDI score (mean, 84 vs $78, P=.29$ ) The totally adverse outcomes were trend to decline in the Epo group (35\% vs $60 \%, P=.21$ ) (Table 4$)$.

\section{Safety Observation}

Participants will have at least three blood samples (prior to $\mathrm{TH}$, end of $\mathrm{TH}$ approximately $4 \mathrm{~d}$ after birth and finished time of Epo/placebo transfusion). We detected serum concentrations of sodium, potassium, calcium, blood sugar, aspartate aminotransferase (AST), alanine aminotransferase (ALT), creatinine (Cr), blood urea nitrogen (BUN), prothrombin time (PT), activated partial thromboplastin time (APTT) and serum total bilirubin. Complete blood counts $(\mathrm{CBC})$ were collected through peripheral blood. Continuous noninvasive blood pressure monitoring and anal temperature data were collected. Hyponatremia is defined as serum sodium lower than $130 \mathrm{mmol} / \mathrm{L}$; hypokalemia is defined as serum potassium lower than $3.5 \mathrm{mmol} / \mathrm{L}$; hypocalcemia is defined as blood calcium lower than $1.8 \mathrm{mmol} / \mathrm{L}$ or free calcium lower than $0.9 \mathrm{mmol} / \mathrm{L}$; hypoglycemia is defined as blood sugar lower than $2.6 \mathrm{mmol} / \mathrm{L}$; hyperbilirubinemia is defined as serum total bilirubin over than $221 \mathrm{umol} / \mathrm{L}$; liver dysfunction is defined as level of AST over than $200 \mathrm{IU} / \mathrm{L}$ or ALT over than $100 \mathrm{IU} / \mathrm{L}$; renal dysfunction is defined as level of $\mathrm{Cr}$ over than 88ummol/L or BUN over than $7.5 \mathrm{mmol} / \mathrm{L}$; coagulation disorder is defined as PT delay over than $3 \mathrm{~s}$ or APTT delay over than $10 \mathrm{~s}$; thrombocytopenia is defined as platelet lower than 100000 per ul; polycythemia is defined 
as hematocrit over than $60 \%$; hypotension is defined as mean arterial pressure (MAP) lower than $40 \mathrm{mmHg}$ or need vasoactive drugs containing; hypothermia is defined as rectal temperature lower than $33.5^{\circ} \mathrm{C}$ over $1 \mathrm{~h}$; hyperthermia is defined as rectal temperature higher than $37.5^{\circ} \mathrm{C}$ over $1 \mathrm{~h}$. The laboratory technician was blinded to the study group.

\section{Statistical analysis}

For accurately analysis of treatment effect, intention-to-treat strategy was used. We analyzed the data by

using SPSS software (SPSS Inc, Chicago, IL). $\chi^{2}$ test or Fisher's exact test (when the count was $\leq 5$ ) were used when compared categorical variables. If continuous variables meet normal distribution, data were expressed as mean $\pm S D$ and counted in $t$ test, otherwise median and inter-quartile range (IQR) were used and used Wilcoxon rank sum test for analyzing. Potential biomarkers comparison between two groups were used 2-sided T test or Mann-Whitney $\mathrm{U}$ test as appropriate. $\mathrm{P}$ values of $<.05$ (2-sided) were considered statistically significant.

\section{Results}

A total of 137 neonates were assessed and $78(57 \%)$ approached for consent. Inclusion participants randomly divided to receive Epo with hypothermia $(n=40)$ or hypothermia alone $(n=38)(F i g .1)$. The two groups were similar in demographic and clinical characteristics (Table 1). Blood gas values and clinical seizures occurring rates were similar at enrollment. All neonates were used whole body cooling for 72 hours, and received cooling at a mean age of 4.8 hours (SD, 4.6) after birth. The first study drug was administered at a mean age of 7.5 hours (IQR, 5.0-16.4) after delivery. Infants received an average of 3.8 doses (SD, 1.9) of Epo. Four patients completed all 7 doses; the remaining did not caused by withdrawn from the trial $(n=3)$, lost intravenous access $(n=8)$, and discharged to home before 14 days $(n=25)$. Average length of hospitalization was 12 days (IQR, 10-16).

\section{TABLE1 Demographic Data and Clinical Characteristics of Study Participants}




\begin{tabular}{lccc}
\hline & $\begin{array}{c}\text { Erythropoietin Group } \\
(\mathrm{n}=40)\end{array}$ & $\begin{array}{l}\text { Control Group } \\
(\mathrm{n}=38)\end{array}$ & $P^{\mathrm{a}}$ \\
\hline Gestational age, wks, mean (SD) & $39.4(1.4)$ & $39.3(1.0)$ & .74 \\
Birth weight, g, mean (SD) & $3312(394)$ & $3329(393)$ & .85 \\
\hline Male, n (\%) & $22(55)$ & $22(58)$ & .80 \\
\hline Caesarean delivery, n (\%) & $16(40)$ & $14(37)$ & .78 \\
\hline 5 min Apgar, n (\%) & $6(15)$ & $9(24)$ & .93 \\
\hline $0-3$ & $21(53)$ & $16(42)$ & \\
$4-6$ & $12(30)$ & $12(32)$ & \\
\hline $7-10$ & $2(5)$ & $4(11)$ & \\
\hline 10 min Apgar, n (\%) & $13(33)$ & $11(29)$ & \\
$0-3$ & $17(43)$ & $17(45)$ & \\
$4-6$ & & & \\
\hline $7-10$ & $7.32(0.07)$ & $7.27(0.21)$ & .29 \\
\hline Blood gas values at enrollment & $6.63(3.87)$ & $7.52(4.53)$ & .48 \\
\hline pH, mean (SD) & $-5.35(4.28)$ & $-8.11(10.27)$ & .24 \\
\hline Lactate, mmol/L, mean (SD) & $20(50)$ & $16(42)$ & .48 \\
\hline Base deficit, mmol/L, mean (SD) & $3.7(3.2-4.7)$ & $3.8(3.0-4.9)$ & .98 \\
\hline Seizures on admission, n (\%) & & & .18 \\
\hline Age at admission, h, median, (IQ range) & $16(40)$ & $14(37)$ & \\
\hline Sarnat grade, n (\%) & $19(48)$ & $13(34)$ & \\
\hline$\square$ & $5(13)$ & $11(29)$ & \\
\hline$\square$ & &
\end{tabular}

a $P$ values for continuous variables are based on 2-sided T test or Mann-Whitney $\mathrm{U}$ test as appropriate. For categorical variables are based on 2 -sided $\chi^{2}$ test.

\section{Changes Of Potential Biomarkers}

We obtained blood samples at before hypothermia (an average age of 7 hours) and after hypothermia (an average age of 82 hours) from participants. Average serum levels in the first available sample from patients of CK and LDH were equal between two groups, but when come to the second sample the CK level was lower in patients with Epo when compared with the controls $(P=0.04)$. As to ionic storm, the level of $\mathrm{Na}^{+}, \mathrm{K}^{+}, \mathrm{Mg}^{2+}$ and $\mathrm{Ca}^{2+}$ were equally distributed between two groups at enrollment, while after intervention, $\mathrm{K}^{+}$and $\mathrm{Mg}^{2+}$ levels of Epo group were higher than control group (Table 2). Average serum levels of $\mathrm{CK}$ and $\mathrm{LDH}$, comparing within each group, showed inclined to normality after treatment, while concentrations of $\mathrm{K}^{+}$and $\mathrm{Ca}^{2+}$ only improved in Epo group (Table 2). 
Table 2

Potential Biomarkers Before and After Treatment

Erythropoietin Group

$(\mathrm{N}=40)$
Control Group

$(\mathrm{N}=38)$

\begin{tabular}{|c|c|c|c|}
\hline \multicolumn{4}{|l|}{ Before treatment ${ }^{b}$} \\
\hline Creatine kinase, IU/L & $2272(1578)$ & $2486(1034-3866)$ & .24 \\
\hline Lactate dehydrogenase, IU/L & $1091(806-1546)$ & $1101(697-1585)$ & .66 \\
\hline $\mathrm{Na}^{+}$level, mmol/L & $140(4)$ & $141(138-142)$ & .18 \\
\hline $\mathrm{K}^{+}$level, $\mathrm{mmol} / \mathrm{L}$ & $4.6(0.6)$ & $4.6(0.8)$ & .99 \\
\hline $\mathrm{Mg}^{2+}$ level, $\mathrm{mmol} / \mathrm{L}$ & $1.0(0.9-1.1)$ & $1.0(0.9-1.1)$ & .83 \\
\hline $\mathrm{Ca}^{2+}$ level, mmol/L & $2.2(2.1-2.3)$ & $2.2(0.2)$ & .07 \\
\hline \multicolumn{4}{|l|}{ After treatment ${ }^{b}$} \\
\hline Creatine kinase, IU/L & $114(52)^{c}$ & $202(108-361)^{c}$ & $.04^{\mathrm{e}}$ \\
\hline Lactate dehydrogenase, IU/L & $492(182)^{c}$ & $507(467-1011)^{d}$ & .17 \\
\hline $\mathrm{Na}^{+}$level, $\mathrm{mmol} / \mathrm{L}$ & $141(4)$ & $142(3)$ & .32 \\
\hline $\mathrm{K}^{+}$level, $\mathrm{mmol} / \mathrm{L}$ & $5.0(0.6)^{e}$ & $4.5(0.6)$ & $.03^{\mathrm{e}}$ \\
\hline $\mathrm{Mg}^{2+}$ level, $\mathrm{mmol} / \mathrm{L}$ & $1.0(0.2)$ & $0.9(0.2)$ & $.02^{\mathrm{e}}$ \\
\hline $\mathrm{Ca}^{2+}$ level, $\mathrm{mmol} / \mathrm{L}$ & $2.3(0.3)^{e}$ & $2.3(2.1-2.4)$ & .24 \\
\hline
\end{tabular}

a $P$ values are based on 2-sided $\mathrm{T}$ test or Mann-Whitney $\mathrm{U}$ test as appropriate.

${ }^{b}$ Variables with normal distribution described by mean (SD), and with skewness distribution described by median (interquartile range).

${ }^{c} P<.0001$, compared with before treatment.

${ }^{\mathrm{d}} P<.005$, compared with before treatment.

e $P<.05$, compared with before treatment.

\section{Neuroimaging Results}

Brain MRI was performed in 65 (83\%) neonatal at a mean age of 7.6 days (SD, 4.8). In the Epo group, 33 infants had a brain MRI examination and all had implemented at least 3 doses of the study drug. BG/W 
score on image results ranged from 0 to 4 (IQR, $0-3)$. Totally brain injury score was in even distribution between two groups (median, 0 vs $0, P=.33$ ) (Table 3 ). There was a trend toward brain injury more localized in basal nuclei (not extend to cortex) among infants who received Epo. Injury to cortex plus basal nuclei comparing with in basal nuclei solely was less common in the Epo than in the control group $(21 \%$ vs $31 \%, P=.046)$.

Table 3

Neonatal Brain MRI BG/W Scores in Erythropoietin Group and Control Group

\begin{tabular}{|c|c|c|c|}
\hline Outcome & $\begin{array}{l}\text { Erythropoietin Group } \\
(N=33)\end{array}$ & $\begin{array}{l}\text { Control Group } \\
(N=32)\end{array}$ & $p^{a}$ \\
\hline Age at MRI, days, mean (SD) & $8(4)$ & $8(6)$ & .89 \\
\hline BG/W scores, $\mathrm{n}(\%)$ & & & .33 \\
\hline 0 & $17(52)$ & $18(56)$ & \\
\hline 1 & $6(18)$ & $2(6)$ & \\
\hline 2 & $3(9)$ & $2(6)$ & \\
\hline 3 & $5(15)$ & $8(25)$ & \\
\hline 4 & $2(6)$ & $2(6)$ & \\
\hline Presence of brain injury, by region & & & .046 \\
\hline basal ganglia or thalamus & $6(18)$ & $2(6)$ & \\
\hline cortex and basal nuclei & $7(21)$ & $10(31)$ & \\
\hline \multicolumn{4}{|c|}{$\begin{array}{l}\text { BG/W indicates basal ganglia/watershed; } 0=\text { normal; } 1=\text { abnormal signal in basal ganglia or } \\
\text { thalamus; } 2=\text { abnormal signal in cortex; } 3=\text { abnormal signal in cortex and basal nuclei (basal ganglia } \\
\text { or thalamus); } 4=\text { abnormal signal in entire cortex and basal nuclei. }\end{array}$} \\
\hline
\end{tabular}


Table 4

Neurodevelopmental Adverse Outcomes at 18 Month of Age

\begin{tabular}{|lll|}
\hline \multicolumn{4}{|c|}{$\mathrm{n} / \mathrm{N}(\%)$} \\
\hline & $\begin{array}{l}\text { Erythropoietin Group } \\
(N=20)\end{array}$ & $\begin{array}{l}\text { Control Group } \\
(N=20)\end{array}$ \\
\hline Total & $7(35)$ & $12(60)$ \\
\hline Death & $3(15)$ & $4(20)$ \\
\hline Cerebral palsy & $1(5)$ & $1(5)$ \\
\hline MDI < 70 & $1(5)$ & $4(20)$ \\
\hline PDI $<70$ & $2(10)$ & $3(15)$ \\
\hline MDI indicates mental development index; \\
\hline PDI indicates psychomotor development index. \\
\hline a $P$ value is based on 2-sided $\chi^{2}$ test. \\
\hline
\end{tabular}

\section{Safety}

No adverse events were ascribed to Epo. Expected adverse events like liver function, renal function, blood coagulation, electrolyte level and hypotension were uniform distributed between two groups. None participants suffered hypoglycemia, hyperbilirubinemia, and hypo/hyper-thermia (Table 5). Red blood cells count and hemoglobin level increased after Epo infusion (Table 6), while neither venous thromboses nor polycythemia were observed. 
Table 5

Adverse Events between Erythropoietin Group and Control Group

\begin{tabular}{|c|c|c|c|}
\hline & $\begin{array}{l}\text { Erythropoietin } \\
\text { Group } \\
\mathrm{n} / \mathrm{N}(\%)\end{array}$ & $\begin{array}{l}\text { Control } \\
\text { Group } \\
\mathrm{n} / \mathrm{N}(\%)\end{array}$ & $p^{a}$ \\
\hline Liver dysfunction (AST > $200 \mathrm{IU} / \mathrm{L}$ or ALT > $100 \mathrm{IU} / \mathrm{L}$ ) & $4 / 27(18)$ & $5 / 28(15)$ & .99 \\
\hline Renal dysfunction $(\mathrm{Cr}>88 \mathrm{ummol} / \mathrm{L}, \mathrm{BUN}>7.5 \mathrm{mmol} / \mathrm{L})$ & $1 / 28(4)$ & $2 / 28(7)$ & .99 \\
\hline Thrombocytopenia (platelet $<100000$ per ul) & 2/33(6) & $5 / 35(14)$ & .43 \\
\hline Polycythemia (hematocrit > 60\%) & $7 / 34(21)$ & $5 / 35(14)$ & .50 \\
\hline Coagulation disorder (PT delay $>3 \mathrm{~s}$, APTT delay $>10 \mathrm{~s}$ ) & $7 / 23(30)$ & $6 / 23(27)$ & .82 \\
\hline Hyponatremia (serum sodium $<130 \mathrm{mmol} / \mathrm{L}$ ) & 1/33(3) & $2 / 28(7)$ & .59 \\
\hline Hypokalemia (serum potassium $<3.5 \mathrm{mmol} / \mathrm{L}$ ) & $8 / 33(24)$ & $3 / 28(11)$ & .17 \\
\hline Hypocalcemia (serum calcium $<1.8 \mathrm{mmol} / \mathrm{L}$ ) & $14 / 31(45)$ & $12 / 27(44)$ & .96 \\
\hline Hypoglycemia (blood glucose $<2.6 \mathrm{mmol} / \mathrm{L}$ ) & 0 & 0 & $N A^{b}$ \\
\hline Hypotension (MAP $<40 \mathrm{mmHg}$ ) & $11 / 35(31)$ & $13 / 32(41)$ & .43 \\
\hline Hyperbilirubinemia (serum total bilirubin $>221 \mathrm{umol} / \mathrm{L}$ ) & 0 & 0 & NA \\
\hline $\begin{array}{l}\text { Hypothermia or hyperthermia (rectal temperature }<33.5^{\circ} \mathrm{C} \text { or } \\
>37.5^{\circ} \mathrm{C} \text { over } 1 \mathrm{~h} \text { ) }\end{array}$ & 0 & 0 & NA \\
\hline \multicolumn{4}{|c|}{$\begin{array}{l}\text { AST, aspartate aminotransferase; ALT, alanine aminotransferase; } \mathrm{Cr} \text {, creatinine; } \mathrm{BUN} \text {, blood urea } \\
\text { nitrogen; PT, prothrombin time; APTT, activated partial thromboplastin time; MAP, mean arterial } \\
\text { pressure; NA, not applicable. }\end{array}$} \\
\hline \multicolumn{4}{|c|}{ a $P$ values are based on 2 -sided $\chi^{2}$ or Fisher's exact test as appropriate. } \\
\hline b $P$ values could not be calculated due to 0 cells. & & & \\
\hline
\end{tabular}


Table 6

Blood Analysis Values Before and After Treatment

\begin{tabular}{|c|c|c|c|}
\hline & $\begin{array}{l}\text { Erythropoietin Group } \\
(N=40)\end{array}$ & $\begin{array}{l}\text { Control Group } \\
(N=38)\end{array}$ & $P^{a}$ \\
\hline \multicolumn{4}{|l|}{ Before hypothermia } \\
\hline RBC count, $10^{9}$ cells per $L$, mean (SD) & $4.9(0.8)$ & $4.7(1.1)$ & .33 \\
\hline Hemoglobin, g/L, mean (SD) & $175(29)$ & $165(37)$ & .20 \\
\hline Hematocrit, \%, mean (SD) & $52(8)$ & $50(11)$ & .40 \\
\hline Platelet level, $10^{9}$ cells per $\mathrm{L}$, mean (SD) & $220(64)$ & $204(111)$ & .44 \\
\hline \multicolumn{4}{|l|}{ After hypothermia } \\
\hline RBC count, $10^{9}$ cells per $L$, mean (SD) & $5.2(0.9)$ & $4.7(1.1)$ & .04 \\
\hline Hemoglobin, g/L, mean (SD) & $182(29)$ & $165(38)$ & .04 \\
\hline Hematocrit, \%, mean (SD) & $53(9)$ & $48(11)$ & .04 \\
\hline Platelet level, $10^{9}$ cells per $\mathrm{L}$, mean (SD) & $207(91)$ & $177(74)$ & .14 \\
\hline \multicolumn{4}{|l|}{ After drug } \\
\hline RBC count, $10^{9}$ cells per $L$, mean (SD) & $5.2(0.7)$ & $4.6(0.8)$ & .03 \\
\hline Hemoglobin, g/L, mean (SD) & $179(26)$ & $159(31)$ & .03 \\
\hline Hematocrit, \%, mean (SD) & $53(7)$ & $48(9)$ & .06 \\
\hline Platelet level, $10^{9}$ cells per $\mathrm{L}$, mean (SD) & $254(151)$ & $310(155)$ & .24 \\
\hline \multicolumn{4}{|l|}{ RBC indicates red blood cell. } \\
\hline a $P$ values based on 2-sided $T$ test. & & & \\
\hline
\end{tabular}

\section{Disscussion}

This is the first clinical trial exploring potential biomarkers including $\mathrm{CK}, \mathrm{LDH}, \mathrm{Na}^{+}, \mathrm{K}^{+}, \mathrm{Mg}^{2+}, \mathrm{Ca}^{2+}$ and a new MRI score system in Epo combined with TH. Our results add to the evidence that Epo in conjunction with TH was associated with hopeful biochemical markers', neuroimagic and neurodevelopmental improvements, including decreased the serum level of $\mathrm{CK}$, increased serum concentrations of $\mathrm{K}^{+}$and $\mathrm{Mg}^{2+}$, localized MRI injury and potentially decreased adverse outcomes of neurodevelopment in long term. 
Epo receptor are expressed on numerous cell types of the central nerve system, including neurons, astrocytes, microglia, and oligodendrocytes.(22) Epo gene expression in the brain tissue is regulated by hypoxia-inducible factor-1 which can activated by ischemia.(23) As Epo binds to receptor, intracellular signaling pathways are triggered. Activation of the Janus kinase-2 (Jak2), nuclear factor kappa B (NF-هB), and mitogen-activated protein kinase (MAPK) pathway may play a role in preventing apoptosis of cell.(5, 24) Evidence suggested that multiple doses of Epo, 250/500/1000/2500 U/kg per dose was tolerable. (25) Our study was consistent with previous trial that no adverse events were attributed to Epo in 1000 $\mathrm{U} / \mathrm{kg}$ per dose through intravenously. There is a physiological RBC destroyed in neonates during the several days after birth, which caused hemoglobin decreased. We found that epo group improved in RBC and hemoglobin count indicates that the decrease can be compensated by Epo. Previous trail showed one patient developed deep vein thrombosis though not ascribed to Epo finally.(9) During our study, no patients developed polycythemia and venous thromboses.

Unlike previous study, we focused on several potential neurological outcome related biomarkers which were widely detected in routine clinical work. Evidence revealed high serum level of CK and LDH was contributed to poor outcome in HIE neonates. $(14,26)$ Our results showed higher level of CK decreased obviously in both group after treatment, while average level of CK in Epo group was closer to normal value than placebo group. Evidently, Epo combined with hypothermia plays an augment effect in reducing tissue damage. While LDH level decreased significantly after intervention in both group, but the percentage change of LDH made no difference between two groups. The widespread distribution in tissues of LDH caused low specificity of LDH when brain damaging may be responsible for the indifference.

Besides biomarkers in serum, $\mathrm{HI}$ triggers ironic storm which may contributes to cell death or injury and is characterized by enhanced $\mathrm{K}^{+}$efflux and $\mathrm{Na}^{+}, \mathrm{Ca}^{2+}$ influx.(16) Actually, comparing with the harmful role of $\mathrm{Ca}^{2+}$ and $\mathrm{Na}^{+}$overload in $\mathrm{HI}$, the function of $\mathrm{K}^{+}$efflux is complicated and unclear. Previous study thought the enhanced $\mathrm{K}^{+}$efflux was an adaptive mechanism by reducing cell excitability during energy depletion.(27) In our results, the serum $\mathrm{K}^{+}$level in Epo group, no matter comparing within group or with the control group, had increased significantly. The serum level of extracellular $\mathrm{Ca}^{2+}$ increased after Epo implemented. We supposed the Epo may play a role in releasing intracellular $\mathrm{Ca}^{2+}$ and $\mathrm{K}^{+}$overload, but the mechanism need further research. $\mathrm{Mg}^{2+}$, regarded as neuroprotective strategy, was ascended in the Epo group, which may predict a positive neuroprotection function.

We used a MRI scoring system which were different from those used in other studies. $(9,28,29)$ In our study, the Epo group 33 infants had a brain MRI examination and all had implemented at least 3 doses of the study drug before examination. Although totally brain injury was in even distribution between two groups, injury to cortex plus basal nuclei comparing with in basal nuclei solely was less common in the Epo than in the control group ( $21 \%$ vs $31 \%, P=.046)$. Commonly, there are two categories of term infant HIE brain damage in MRI image. One is characterized as BG (ganglia or thalamus) damage, which is usually due to acute $\mathrm{HI}$ and relates to the worst outcomes of motor and cognitive function. The other is 
watershed region damaging in dominantly, which is most occurring after long-term incomplete asphyxia and is relates to the defect of cognitive function.(30) Epo may play a role in decreasing damage spread to cortex through improving arteries' perfusion.

The loss of follow-up is the most important limitation in our study. Despite our best efforts, only forty patients $(40 / 78,51 \%)$ succeed in achieving 18-month follow up in the end. The remaining did not because of parents refused gone back to hospital for assessment at 18-month $(n=16)$, children resided out of Shanghai $(n=10)$, parents' reserved phone number was invalid $(n=8)$, and chose follow up in other hospital $(n=4)$. Although had not reached a significant difference between two groups, the results of Bayley II developmental scale showed that the Epo group were likely to perform better in MDI score (mean, 88 vs $81, \mathrm{P}=.23$ ) and $\mathrm{PDI}(\mathrm{mean}, 84$ vs $78, \mathrm{P}=.29$ ) score and totally adverse outcomes were trend to decline in the Epo group ( $35 \%$ vs $60 \%, P=.21)$.

Besides the defect of follow-up data, the relatively small scale of this trial is another important limitation. Our study need authentication in a bigger trial with an adequate sample size and multicenter to lesson bias, with a higher completion rate of follow-up data in long-term, with extender biomarkers for an accurately predicting outcomes in short term and with standard electrophysiological data collection.

\section{Conclusions}

Among HIE neonates receiving $\mathrm{TH}$, high doses of erythropoietin $(1000 \mathrm{U} / \mathrm{kg})$ administrated intravenously every other day over two weeks may result in improvement of tissue damage and ionic disequilibrium, less MRI brain injury and may lead to potential improved long-term neurological outcomes.

\section{Abbreviations}

Epo: Erythropoietin; TH: therapeutic hypothermia; HIE: hypoxic-ischemic encephalopathy; BG/W: basal ganglia/watershed; Bayley IIखBayley Scales of Infant Development II; MDI: intelligence development index; PDI: psychomotor development index; CK: creatine kinase; r-Hu-Epo: human recombinant erythropoietin; LDH: lactate dehydrogenase; AST囚aspartate aminotransferase; ALT: alanine aminotransferase; Cr: creatinine; BUN: blood urea nitrogen; PT: prothrombin time; APTT: activated partial thromboplastin time; MAP: mean arterial pressure.

\section{Declarations}

\section{Ethics approval and consent to participate}

This study was approved by the Ethics Committee of Children's Hospital of Fudan University (Approved No. of ethic committee区[2012]081). Written informed consent was obtained from the parents.

\section{Consent for publication}


Not applicable.

\section{Availability of data and materials}

The datasets used and analysed during the current study are available from the corresponding author on reasonable request.

\section{Competing interests}

The authors declare that they have no competing interests.

\section{Funding}

No funding have been received in the study.

\section{Authors' contributions}

LSW take responsibility for the integrity of the work as a whole from inception to published article. LYZ participated the design of the study, coordinated data collection, performed data analyses, and drafted the initial manuscript. JQS conceptualized and designed the study. BXH, PZ, GQC, WHZ and CML provided substantial contributions to acquisition of data or data analysis. All authors read and approved the manuscript.

\section{Acknowledgments}

The authors thank all parents and infants who participated in the study and all team members in charge of data collection.

\section{References}

1. Liu L, Oza S, Hogan D, Perin J, Rudan I, Lawn JE, et al. Global, regional, and national causes of child mortality in 2000-13, with projections to inform post-2015 priorities: an updated systematic analysis. Lancet. 2015;385(9966):430-40.

2. Tagin MA, Woolcott CG, Vincer MJ, Whyte RK, Stinson DA. Hypothermia for neonatal hypoxic ischemic encephalopathy: an updated systematic review and meta-analysis. Arch Pediatr Adolesc Med. 2012;166(6):558-66.

3. Edwards AD, Brocklehurst P, Gunn AJ, Halliday H, Juszczak E, Levene M, et al. Neurological outcomes at 18 months of age after moderate hypothermia for perinatal hypoxic ischaemic encephalopathy: synthesis and meta-analysis of trial data. BMJ. 2010;340:c363.

4. Shankaran S, Pappas A, McDonald SA, Vohr BR, Hintz SR, Yolton K, et al. Childhood outcomes after hypothermia for neonatal encephalopathy. N Engl J Med. 2012;366(22):2085-92.

5. Digicaylioglu M, Lipton SA. Erythropoietin-mediated neuroprotection involves cross-talk between Jak2 and NF-kappaB signalling cascades. Nature. 2001;412(6847):641-7. 
6. Gonzalez FF, Larpthaveesarp A, McQuillen P, Derugin N, Wendland M, Spadafora R, et al. Erythropoietin increases neurogenesis and oligodendrogliosis of subventricular zone precursor cells after neonatal stroke. Stroke. 2013;44(3):753-8.

7. Zhang H, Fang X, Huang D, Luo Q, Zheng M, Wang K, et al. Erythropoietin signaling increases neurogenesis and oligodendrogenesis of endogenous neural stem cells following spinal cord injury both in vivo and in vitro. Mol Med Rep. 2018;17(1):264-72.

8. Wu YW, Bauer LA, Ballard RA, Ferriero DM, Glidden DV, Mayock DE, et al. Erythropoietin for neuroprotection in neonatal encephalopathy: safety and pharmacokinetics. Pediatrics. 2012;130(4):683-91.

9. Wu YW, Mathur AM, Chang T, McKinstry RC, Mulkey SB, Mayock DE, et al. High-Dose Erythropoietin and Hypothermia for Hypoxic-Ischemic Encephalopathy: A Phase II Trial. Pediatrics 2016;137(6).

10. Zhou W, Cheng G, Shao X, Liu X, Shan R, Zhuang D, et al. Selective Head Cooling with Mild Systemic Hypothermia after Neonatal Hypoxic-Ischemic Encephalopathy: A Multicenter Randomized Controlled Trial in China. The Journal of Pediatrics. 2010;157(3):367-72.

11. Sarnat HB, Sarnat MS. Neonatal encephalopathy following fetal distress. A clinical and electroencephalographic study. Arch Neurol. 1976;33(10):696-705.

12. Jacobs SE, Morley CJ, Inder TE, Stewart MJ, Smith KR, McNamara PJ, et al. Whole-body hypothermia for term and near-term newborns with hypoxic-ischemic encephalopathy: a randomized controlled trial. Arch Pediatr Adolesc Med. 2011;165(8):692-700.

13. Shankaran S, Laptook AR, Ehrenkranz RA, Tyson JE, McDonald SA, Donovan EF, et al. Whole-body hypothermia for neonates with hypoxic-ischemic encephalopathy. $\mathrm{N}$ Engl J Med. 2005;353(15):1574-84.

14. Hayakawa M, Ito Y, Saito S, Mitsuda N, Hosono S, Yoda H, et al. Incidence and prediction of outcome in hypoxic-ischemic encephalopathy in Japan. Pediatr Int. 2014;56(2):215-21.

15. Mehta A, Chawla D, Kaur J, Mahajan V, Guglani V. Salivary lactate dehydrogenase levels can provide early diagnosis of hypoxic-ischaemic encephalopathy in neonates with birth asphyxia. Acta Paediatr. 2015;104(6):e236-40.

16. Hansen AJ. Effect of anoxia on ion distribution in the brain. Physiol Rev. 1985;65(1):101-48.

17. Khanna A, Kahle KT, Walcott BP, Gerzanich V, Simard JM. Disruption of ion homeostasis in the neurogliovascular unit underlies the pathogenesis of ischemic cerebral edema. Transl Stroke Res. 2014;5(1):3-16.

18. Hoffman DJ, Marro PJ, McGowan JE, Mishra OP, Delivoria-Papadopoulos M. Protective effect of MgSO4 infusion on nmda receptor binding characteristics during cerebral cortical hypoxia in the newborn piglet. Brain Res. 1994;644(1):144-9.

19. Sugimoto J, Romani AM, Valentin-Torres AM, Luciano AA, Ramirez KC, Funderburg N, et al. Magnesium decreases inflammatory cytokine production: a novel innate immunomodulatory mechanism. J Immunol. 2012;188(12):6338-46. 
20. Barkovich AJ, Hajnal BL, Vigneron D, Sola A, Partridge JC, Allen F, et al. Prediction of neuromotor outcome in perinatal asphyxia: evaluation of MR scoring systems. American Journal of Neuroradiology 1998;19(1.):143.

21. Gollenberg AL, Lynch CD, Jackson LW, McGuinness BM, Msall ME. Concurrent validity of the parentcompleted Ages and Stages Questionnaires, 2nd Ed. with the Bayley Scales of Infant Development II in a low-risk sample. Child Care Health Dev. 2010;36(4):485-90.

22. Bond WS, Rex TS. Evidence That Erythropoietin Modulates Neuroinflammation through Differential Action on Neurons, Astrocytes, and Microglia. Front Immunol. 2014;5:523.

23. Frede S, Freitag P, Geuting L, Konietzny R, Fandrey J. Oxygen-regulated expression of the erythropoietin gene in the human renal cell line REPC. Blood. 2011;117(18):4905-14.

24. Jeong JE, Park JH, Kim CS, Lee SL, Chung HL, Kim WT, et al. Neuroprotective effects of erythropoietin against hypoxic injury via modulation of the mitogen-activated protein kinase pathway and apoptosis. Korean Journal of Pediatrics. 2017;60(6):181.

25. Rogers EE, Bonifacio SL, Glass HC, Juul SE, Chang T, Mayock DE, et al. Erythropoietin and Hypothermia for Hypoxic-Ischemic Encephalopathy. Pediatr Neurol. 2014;51(5):657-62.

26. Yum SK, Moon C, Youn Y, Sung IK. Changes in lactate dehydrogenase are associated with central gray matter lesions in newborns with hypoxic-ischemic encephalopathy. The Journal of MaternalFetal \& Neonatal Medicine 2017;30(10.):1177-81.

27. Yu SP, Yeh CH, Sensi SL, Gwag BJ, Canzoniero LM, Farhangrazi ZS, et al. Mediation of neuronal apoptosis by enhancement of outward potassium current. Science. 1997;278(5335):114-7.

28. Elmahdy H, El-Mashad A, El-Bahrawy H, El-Gohary T, El-Barbary A, Aly H. Human recombinant erythropoietin in asphyxia neonatorum: pilot trial. Pediatrics 2010;125(5.):e1135-42.

29. Mulkey SBMP, Ramakrishnaiah RHM, McKinstry RCMP, Chang TM, Mathur AMM, Mayock DEM, et al. Erythropoietin and Brain Magnetic Resonance Imaging Findings in Hypoxic-Ischemic Encephalopathy: Volume of Acute Brain Injury and 1-Year Neurodevelopmental Outcome. Journal of Pediatrics The. 2017;186:196-9.

30. Rutherford M, Malamateniou C, McGuinness A, Allsop J, Biarge MM, Counsell S. Magnetic resonance imaging in hypoxic-ischaemic encephalopathy. Early Hum Dev. 2010;86(6):351-60.

\section{Figures}




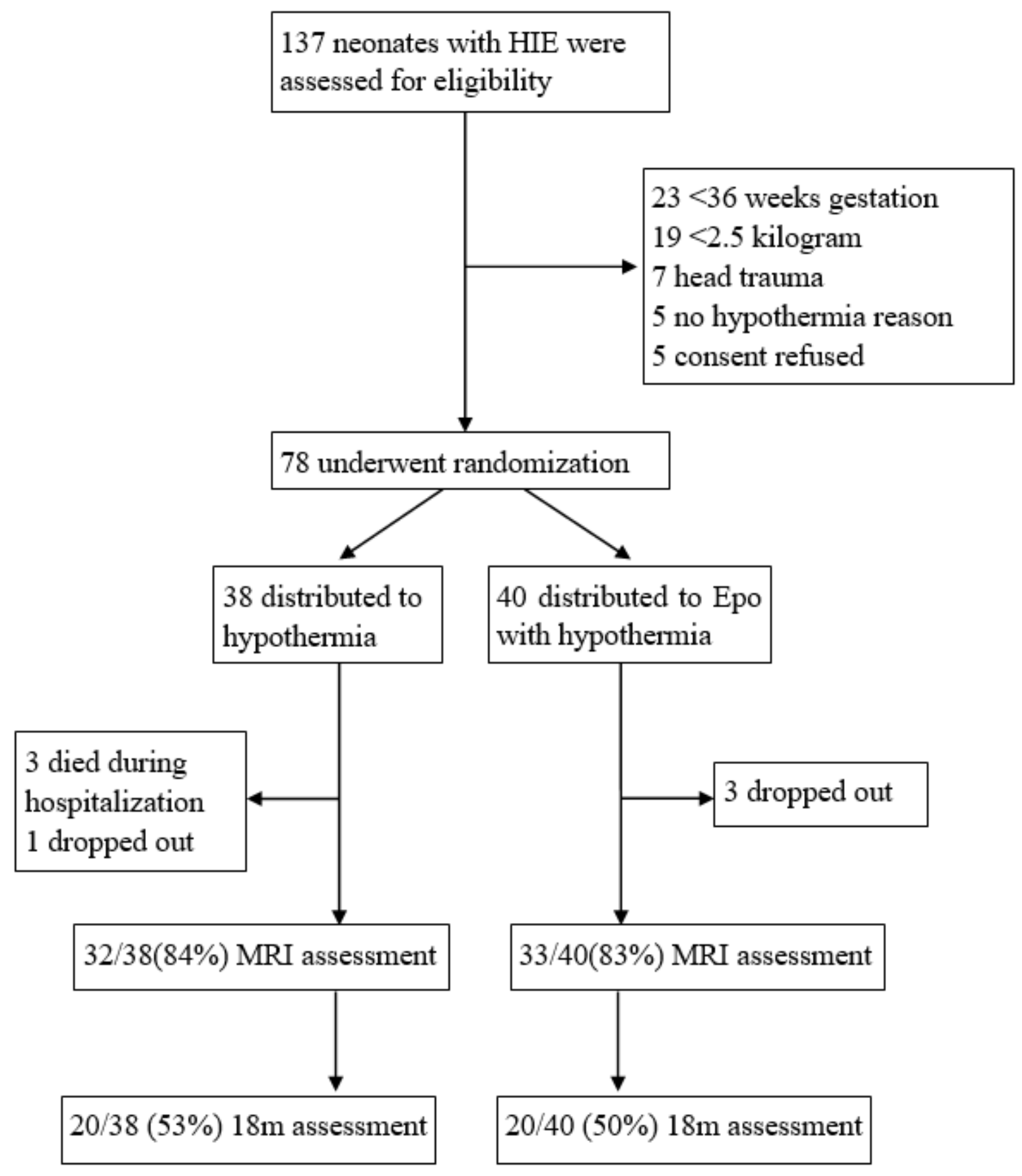

Figure 1

Trial profile. 3 died during hospitalization: 2 died of persistent pulmonary hypertension, 1 died of multiple organ dysfunction syndrome. Dropped out, parents requested participants be withdrawn from the trial.

\section{Supplementary Files}

This is a list of supplementary files associated with this preprint. Click to download. 
- CONSORTChecklistEpoCombinewithTHinNeonatalHIE.doc 